\title{
Whose Flourishing? Which Aristotelianism?
}

\author{
Andrew Sabl
}

Published online: 16 October 2013

(C) Springer Science+Business Media New York 2013

Much of what Philip Gorski says in his piece is undeniably true. I agree that a rigid distinction between facts and values cannot be maintained, and that the researcher's claim to be maintaining it often masks, intentionally or unintentionally, an attachment to values that are not openly avowed and defended. I further agree that one of the main culprits behind the mistaken belief that the fact-value distinction is absolute and desirable is Kant, along with the Kantian metaethics imported into sociology by Weber.

However, I am more skeptical of Gorski's stronger claim: that social science (in cooperation with other disciplines) can discover criteria of human flourishing, rooted in observation, that can guide empirical inquiry and social policy. My skepticism stems from doubt that an Aristotelian mode of inquiry yields sufficient agreement among scholars, on any but the most vague and unhelpful level, regarding what human flourishing consists in. That social science typically claims to measure not our degree of flourishing but more minimal and countable outcomes - wealth, life expectancy, educational completion rates, the Gini index of inequality - reflects not a failure to realize that human flourishing involves more than such things but rather a pragmatic accommodation to past experience, and future prospects, of profound disagreement regarding what that "more" is.

One may start with Hume. Gorski is of course correct that Hume is often cited as an originator of the fact-value distinction. But we should pause to note how unlikely a story about Hume's actual intentions this intellectual myth represents. Hume's Treatise is subtitled "an Attempt to introduce the Experimental Method of Reasoning into Moral Subjects." It would be very odd if someone who proclaimed this as his aim

\footnotetext{
A. Sabl $(\bowtie)$

Program in Ethics, Politics, and Economics, Yale University, New

Haven, CT 06520, USA

e-mail: andrew.sabl@yale.edu
}

had had in mind an absolute distinction between fact and value. Of course, the word "moral" in Hume's time had a broader meaning that it does now; the term covered many things that we would call social and cultural. But Hume's subject in the third book of the Treatise is not just society or culture but, overwhelmingly, morals in a sense recognizable to us: an account of human virtue's foundations, purpose, and proper objects.

As Alasdair MacIntyre has noted in the - dissenting, but accurate - article Gorski cites, Aristotle made use of "bridge notions" between is and ought ("wanting, needing, desiring, pleasure, happiness, health"), and so did Hume. Hume, as MacIntyre convincingly argues, continued the Aristotelian tradition in the sense of wanting to ground ethics in human psychology, though the way he did so was very nonAristotelian: Hume's central bridge notion was not human happiness or health but observable, common human interests, with justice and other social virtues consisting in what furthered those interests. In his later Enquiry Concerning the Principles of Morals, Hume likewise avowed an "experimental method" but proposed a somewhat different bridge. He set out to examine our opinions of personal merit, our sentiments of praise and blame, with a view to correcting them, again through observation (for instance, the desire to make money may cease to seem a damnable vice once we come to appreciate the social benefits that this passion makes possible). As a foundation for ethics, the study of permanent human interests, corrected through observation, might seem more plausible than the study of what people praise, similarly corrected. But Adam Smith in his Theory of Moral Sentiments essentially traversed Hume's second bridge, not the first; I shall give some reasons at the end of this reply for thinking this a sensible choice for certain, social purposes. For now it is enough to note that there are Humean methods, quite distinct from those of Aristotle, for bridging facts and values - methods that could be said to improve on Aristotle's, 
not in Gorski's sense of being open to the equality of all human beings (as Hume was not, consistently) but in being designed to reach agreement for certain conventional purposes among people who disagree on ultimate questions.

When trying to design a scheme of value and apply it to a contemporary society, it is crucial to acknowledge the degree to which the members of such societies disagree, profoundly and pervasively, regarding the ultimate human goods. Throughout its many parts, and for all its laudable ecumenicism, Gorski's essay displays, I am afraid, a certain unwillingness to do so.

It would be perverse to deny that some assessments of whether a human animal is flourishing jump out at us through observation, and convey ethical content. Careful and unprejudiced observation can quickly discover whether someone is dead or dying, diseased, injured, severely malnourished, imprisoned or undergoing torture, or the contrary of these states. That the former states are palpably bad, in some intuitive sense, can motivate the observer convinced of their badness to become attached to some basic human rights (life, liberty, basic nutrition and health). It can likewise motivate what Michael Walzer has called a "thin" political agenda that forbids aggressive war, genocide, gulags, deliberate famines, and extreme forms of tyranny but not much else. But beyond these states of obvious health or sickness, freedom or constraint, to assess a life as flourishing or, conversely, stunted is to bring to it our opinions as to how people ought best to live. And while such opinions may be drawn from avowed or unavowed analyses that draw on Aristotle, or at least imitate his method, they will also and inescapably involve our idiosyncratic ideological, religious, and moral views.

Take Martha Nussbaum's list of "central human goods," which Gorski cites: "life, health, bodily integrity, imagination and thought, emotional expression and attachment, the use of practical reason, affiliation with others, protection of other species, play, and political voice." Compare this with John Finnis' list of "the basic forms of human good" in his 1980 book Natural Law and Natural Rights: life, knowledge, play, aesthetic experience, sociability (friendship), practical reasonableness, and religion. Though Nussbaum and Finnis are both self-styled Aristotelians, their lists do not match. And the lack of match only becomes clearer as the two authors explicate what they mean. Nussbaum, originally influenced by the early Marx and more recently by Rawlsian liberalism, includes a great many goods involving bodily health, satisfaction, and liberty, as well as nondiscrimination (which she takes to be part of affiliation) and protection of other species; in defining goods like practical reason, Nussbaum interprets them in largely liberal ways involving freedom of conscience. Finnis, starting from a natural law background-i.e. a Catholic or Thomist one, though Finnis insists that the goods he lists and the reasons for their goodness can be appreciated regardless of one's religious background - hardly acknowledges the needs and pleasures of the body; does not say much about nondiscrimination because he does not regard as fundamental what Rawls called the "social bases of self-respect" (indeed, does not consider self-respect itself particularly important); and considers religion - and not just freedom of religion, as with Nussbaum - absolutely central to human existence. Notably, he interprets practical reason in a way that casts pervasive doubt on the value of pursuing pleasure or subjective happiness; for that pursuit, outside very narrow limits, often conflicts, in Finnis' view, with one or another basic human good. The point is not that either Nussbaum's or Finnis' list of human goods is necessarily wrong but that they cannot both be fully right. The difference between them concerns the question, not small, of whether human beings have souls whose needs must be satisfied or whether, on the contrary, all of importance to us is contained in our bodies (including our mental processes, which Nussbaum takes to be essentially bodily as well). We cannot properly assess whether a human life is good without taking a position on that question. But it is a question that no social science, indeed no human activity based on observation, can settle.

If, in spite of this, we attempt to base assessments of human flourishing on observation alone, we will end up reasoning in a circle or placing more weight on one observed fact or another than it can bear. Thus Gorski congratulates Martin Seligman for acknowledging that subjective happiness or "positive emotion" is only one among many measures of well-being. But he also congratulates Richard Easterlin, who criticizes economic growth on the grounds that it does not maximize "self-reported levels of individual happiness." (Easterlin, by the way, has been criticized by Dierdre McCloskey and others for using scales that do not allow sufficient room for fairly happy people to report further increases in happiness. One can only add to such criticisms the observation, known to generations of critics of Benthamite utility though not apparently to Easterlin or his many fans, that no quantitative measure of "happiness" can be particularly reliable or even meaningful.) But one cannot have it both ways. If subjective happiness is a poor proxy for human flourishing, it will also constitute a poor standpoint from which to criticize the desire to gain more wealth. Moreoever, if Gorski's view is in fact that greater wealth, beyond a certain point, does not constitute genuine human development, he should, to be consistent, savagely criticize the UN's Human Development Index, instead of praising it as he does.

Again, the point is not to criticize Gorski's particular proposed measures of human flourishing. It is to question whether any such measure exists that will not be either ideological, circular, or based, as in Hume, on our starting opinions of what makes for a happy life - corrected, as Hume puts it in the his moral Enquiry, by "argument and reflection."

Perhaps there is some measure or set of measures out there that will succeed in capturing, and making amenable to 
observation, the fullness of human flourishing even though contemporary social science has so far failed to do so. Gorski's canvass of the classics of social theory, which he rightly takes to have been concerned with ethical value and in particular with human flourishing (none, except for Weber, even disclaiming such concerns), leads him to suggest that contemporary social theorists should emulate their forbears and grapple with the big questions that today's researchers aim to bracket. But his account of past social theorists proves too much. It is certainly plausible to read Marx on the one hand or Durkheim on the other as an ethical naturalist and indeed, in each case, as some kind of Aristotelian. (Gorski's claim that Tocqueville also qualifies on account of his mild republicanism alone seems more controversial, as Tocqueville gives no systematic account of human flourishing.) But the problem is that Marx and Durkheim were different kinds of ethical naturalist. Their explorations suggested to these two profound but opposed minds two very different accounts of what human beings most needed to flourish and what in modern society most threatened their flourishing. We have not too few insights to guide a social-science research agenda, but too many.

The young Marx, while no economic determinist, thought it was inherently dehumanizing for one person to sell his or her labor to another for wages: do we want to ground our social science agendas on that assumption? For Durkheim, as Gorski notes, suicide was a canary in a sociological coalmine because it was a sign of a literally fatal imbalance between moral regulation and social regulation. Yet would we really want to make infrequent suicide our measure of a flourishing society? If so, according to the latest figures I could find, the citizens of Greece in 2011 were five times as flourishing as those of France. And even if we wanted to adopt either of these great thinker's theories as the driver of our agenda, we could not adopt both-and the demand to study human flourishing does not tell us which to plump for.

At issue here is what lesson to draw from disagreement and whether it is wise to act on what might be called scientific faith. Faced with a variety of disparate, largely clashing conceptions of human flourishing, Gorski is prone to see an exciting and dynamic research program. Others of more skeptical temperament might quite reasonably draw from the same disparity the conclusion that such a program is likely to disappoint, that the enterprise of speculation regarding human flourishing involves endless individual insight but little collective advance in knowledge. Whether each of many past social theorists came up with a rich account of human flourishing is, from this skeptical perspective, beside the point. The question is whether the tradition of social theorizing has yielded ever-greater agreement regarding what constitutes human flourishing or how to achieve it. It has not. And absent some reason to believe that contemporary scholars of society are, individually or collectively, smarter, more penetrating, or better able to synthesize social facts than Marx or Durkheim, we might therefore derive from that tradition the suspicion that we cannot either. And if we cannot, we cannot make human flourishing, as opposed to some more prosaic and specific set of ends or values, the dependent variable in a social-science investigation. The aspiration to ground social inquiry on a shared view of what constitutes human flourishing is like the aspiration to build a perpetual motion machine. While it is impossible not to like the goal in principle, and perennial opposition to pursuing it can be made to sound petty or negative, sober people have stopped aiming at it not because it is unattractive but because we have excellent reasons to think it unattainable.

To be sure, one can imagine ways of dealing with this kind of disagreement. Most radically, under a kind of scholarly individualism, not to say anarchism, we could imagine each scholar formulating his or her own reflections on human flourishing, with a research program to match. Social science on this model would abandon any aspiration to ever-greater agreement; instead of social scientists' seeing themselves as participants in one or another progressive research program, they would aspire to be nothing more or less than idiosyncratic, insightful empirical essayists. If for no other than professional reasons, involving the desire for status on the one hand and the human love of fellow feeling on the other, this solution is unstable. It will tend to collapse, and in fact has largely collapsed, into a sectarian solution of coherent, plausible, incompatible schools. Those devoted, broadly speaking, to Marx's or Durkheim's views of human flourishing (or Nussbaum's, or Finnis', or Tocqueville's) might find a home in a school of social thought with its own research questions, its own favorite social indicators and yardsticks; members of each school might then proclaim a given society, or piece of society, well or badly off according to its own standards, not recognized by others. This, of course, is one way of describing the status quo, and some enjoy it. But a social science factionalized in this way is manifestly unlikely to "tell us anything about how we ought to live and what makes a good society" that our pre-existing ideologies have not already largely supplied. It is partly their tendency to reflect existing moral and ideological disagreements that have caused many of the social sciences, such as sociology and anthropology, to lose their status as arbiters of social debates. And one could argue, depressingly, that precisely its willed obtuseness in the face of moral and ideological disagreements, indeed its failure to acknowledge the big questions that occasion those disagreements, is what has let economics retain its high status. Because the walls surrounding economics are invisible-impermeable value judgments shelter investigators who cannot even perceive them as value judgments - they are all the harder to breach.

Given the hazards of the partisan approach, there is something to be said for seeking grounds that are low but apparent to all, for looking at the causes or preconditions of things that many human beings in fact value (pun intended). Thus the UN's 
Human Development Index measures a weighted average of GDP per capital at purchasing-power-parity, life expectancy, and expected years of schooling, not because anyone thinks these are the only sources of human flourishing but because the designers of the index have acknowledged that other things one might value (involving, for instance, economic equality, poverty reduction, and opportunities for women) involve too much controversy to ground a global consensus. Recognizing that the choice of how to weigh these other factors is moral and ideological, not scientific, the UN Development Program lets online users produce their own indices by adding in such measures, or subtracting some of the classic ones if they like, as well as changing the rather arbitrary weights that the Program has placed on the three consensus indicators. How one does this-how one assesses the relative importance of a series of reliable numbers, each of which very plausibly matters greatly to human flourishing - makes a vast difference to how countries are ranked and evaluated. And it is a difference that I cannot imagine any social-scientific inquiry being able to adjudicate.

In a middle ground, we could imagine rough agreement on a variety of indicators that a broad range of scholars might think relevant to human flourishing (with other scholars being free to gather information on indicators whose relevance is more controversial, e.g. those relating to religiosity, or to the prevalence or scarcity of "traditional" families). Social inquiry could then examine these indicators as either independent or dependent variables. Scholars or schools of scholars would be held to standards of clarity and transparency regarding which variables they intended to place most emphasis and weight on, as well as the ideological and moral choices involved in those intentions. One model here would be the do-it-yourself UN Development Program index, but another would be current scholarship in comparative democratization. Hardly anyone studying the progress of democracy considers the enterprise value neutral: democracy is a "thick" or morally loaded concept if ever there was one, and the achievement, survival, and deepening of democracy are generally considered good things. But there is enough disagreement about the details of what counts as fully democratic governance and which countries most thoroughly exemplify its perfection that scholars have come to use multi-dimensional measures so that scholarly work can progress in spite of profound political disagreements. As with the concept of flourishing, the value-laden concept of democracy embodies political disagreement rather than settling it. That does not mean that attachment to either concept lacks value, just that a variety of clashing research programs and incompatible policy proposals can march under its motley banner.

In all these matters there is likely to be a sharp tradeoff between consensus and depth. The more an account of human flourishing possesses true insight, the hallmark of which is unpredictability from a partisan or conventional point of view, the less suitable it will be as a rallying point for broad agreement among scholars, not to mention the students, funders, and popularizers whose support scholars require. The search for lowest common denominators, for measures of well-being that are admittedly blunt but uncontroversially useful, may reflect not skepticism or reductionism but rather the desire for the kind of broad agreement on which one may found a discipline, or at least a school. (This is why Durkheim's suicide criterion, though famous, never caught on.) The aspiration to something more than empirical essays requires intellectual compromise, a shading of the strong flavors that make a menu hard to franchise.

This brings us back to Hume and his two distinct factual-cummoral inquiries into human values: one based on universal human interests, one based on opinions that Hume hoped would be universal (once corrected for errors and local biases) regarding the bases of human merit, the proper occasions for praise and blame. The human-interest standard surely seems more solid than the praise and blame standard, more likely to yield permanent insight, for the purpose of substantive ethical and political inquiry. The former standard may also yield sharper insights into strategy or policy, more useful advice to those in a position to choose among alternatives or shape new ones. But the second type of inquiry, suitably transformed, may be a more fruitful model for organizing social science research programs.

That is, Hume's inquiry into praise and blame may have a virtue for us as scholars that was not available to, or imagined by, Hume himself. It is not actually true that all reasonable people can be brought, through careful reasoning, to agree on the fundamental categories of human character. Hume thought that all assessments of virtue, except for perverse and biased ones whose prevalence Hume blamed as usual on religion, could be reduced to the question of what was useful or immediately agreeable to one's self or others. But many have disputed this claim (and any Aristotelian must reject it). Conceptually speaking, it would seem that any attempt to summarize what human beings find praiseworthy must face an impossible dilemma: for such an account to be interesting, as opposed to hopelessly vague or tautological, it will have to have an edge to it, will have to be the kind of thing that could be wrong - but given that, some will claim that it is, in fact, wrong. (What makes Hume's second Enquiry interesting is precisely what makes it impossible as the basis for a universal consensus: its anti-monotheistic ethics, its denial that humility, self-denial, and the other "monkish" virtues are, in fact, virtues.) Whether or not this conceptual trap is universal, something like it seems to operate in practice: all tautologies are tautologies and all non-tautologies are controversial. In fact, the impossibility of universal agreement on praiseworthy qualities of character lies behind the decision of the UN, influenced more by Sen than by Nussbaum, to reject the direct quest for human flourishing or human virtue - two things which for any Aristotelian, though not for Hume, are intimately connected - in favor of Sen's method of expanding our definition of freedom so that not only wealth but education, 
health, and social opportunities can be seen as means of achieving whatever goals each of us may have.

However, while the standard of universal praise and blame may not be viable as a foundation for value, it does serve as an excellent proxy for the local, practical question of which sorts of inquiries a community is likely to regard as worth pursuing, worth reading about, and worth funding. If, for example, most Americans think that dynamic leadership, bold in proposing changes to large organizations and fearless in pushing through those changes in the face of conflicting interests and opinions, is a good thing, that does not prove that this quality of character is in general a good thing - but it does prove that books on leadership (in that sense) will have an audience, that they will be assigned in classes, that government grantmaking agencies are unlikely to face the wrath of politicians if they fund projects on how to discern, cultivate, or promote such leadership. And the same goes for other qualities that might or might not be considered praiseworthy: a fervent desire to gain wealth (or its absence, or something in between); a tendency to question social conventions (or, conversely, ease at grasping them and a disposition to observe them); religiosity (or irreverence); and so on. The search for consensus on which of these qualities is good for human beings will not yield the truth regarding whether it is good. But it will help us discover whether the preponderance of influential opinion in a community that concerns us believes that it is good. And it is only on such beliefs that durable social-scientific agendas can be founded.

Andrew Sabl is Visiting Professor in the Program in Ethics, Politics, and Economics at Yale University and the author, most recently, of Hume's Politics: Coordination and Crisis in the History of England (Princeton). 